\title{
Apoptosis and Necrosis of Human Breast Cancer Cells by an Aqueous Extract of Euphorbia hirta leaves
}

\author{
Bandana Behera1, Jyoshna Dash', Debasish Pradhan1*, Gitanjali Tripathy², Rakesh Pradhan' \\ 'Department of Pharmaceutical Sciences, Utkal University, Vani-Vihar, Odisha, INDIA. \\ 2Department of Pharmacy, Govt Polytechnic, Chandrasekharpur, Bhubaneswar, Odisha, INDIA.
}

\begin{abstract}
Introduction: Traditional medicines for mammary tumour are unreasonable and have genuine symptoms. Non-ordinary normal medications have increased wide acknowledgment because of their assurance of a cure with negligible or no symptoms, however minimal experimental confirmation exists. One such basic cure is the leaves of the Euphorbia hirta plant. Methods: It is initially reported utilization of the fluid concentrate of Euphorbia hirta leaves breast cancer cells. The capacity of the concentrate to impel apoptosis and corruption in the human bosom malignancy cell line MCF-7, contrasted with typical human skin fibroblasts (MDA MB-231), was dictated by morphological changes in the cells utilizing light microscopy, DNA fragmentation, and brilliant stains (Annexin $V$ and Propidium lodide) utilizing Flow Cytometry and fluorescent microscopy. Results: Apoptosis was instigated in both cells, and more in MCF-7, when they were treated with $25 \%$ and half concentrate, while rot was watched mostly after presentation to raised concentrate fixations (75\%). DNA discontinuity came about for both cells, in a period and dosage subordinate way. Both cells, at
\end{abstract}

all concentrate fixations, demonstrated no critical contrasts in the quantity of living, dead, apoptotic, and necrotic cells. Conclusion: At long last, the outcomes might show that apoptotic changes in MCF-7 might be free of caspase-3, which is included in apoptosis and is inadequate in MCF-7 cells.

Key words: Apoptosis, Aqueous extract, Euphorbia hirta leaves, Human breast cancer cells, Necrosis.

Correspondence :

Dr. Debashis Pradhan,

Department of Pharmaceutical Sciences, Utkal University, Vani-Vihar, Odisha, INDIA.

Phone no: 9861137772

E-mail: deba_udps@yahoo.co.in

DOI: 10.5530/jyp.2016.3.4

\section{INTRODUCTION}

Cancer is a major cause of death worldwide with breast cancer being the most common cancer and a leading cause of death in females in many parts of the world. Both conventional and non-conventional treatments of cancer are widely used. Non-conventional treatments are attractive due to their claim to counteract the problems of conventional treatments, such as high cost and serious side effects.

Many natural dietary agents, including vegetables, fruits, herbs, and spices have been used in traditional medicines, as non-conventional treatments, for thousands of years, but without sufficient scientific proofs. If effective, natural agents might lead to the development of natural and novel drugs with low or no side effects.

Numerous epidemiological, biological and clinical studies ${ }^{1}$ indicate a strong correlation between dietary factors and lower risk for developing cancer. Dietary factors can prevent cancers, and they, on the other hand, can induce cancers.

Many dietary agents, such as curcumin (in turmeric) and epigallocatechingallate (in green tea), have been shown ${ }^{2}$ to cause induction of apoptosis and cell cycle arrest in many types of cancer cells without affecting normal cells. Cruciferae or Brassicaceae vegetables, such as garden cress (LepidiumEhirta, [Euphorbia hirta]), and their active ingredients have been found to stimulate apoptosis in cancer cells $s^{5}$, thereby killing cancer cells specifically without harming normal healthy cells.

The leaves of the Euphorbia hirta plant, which are used in folk remedies, have many activities including thermogenic, depurative, rubefacient, tonic, aphrodisiac, abortive, ophthalmic, diuretic, and contraceptive. ${ }^{7}$ They are useful as poultices for sprains and in leprosy, ophthalopathy, leucorrhoea, scurvy, seminal weakness, bronchial asthma, cough, and hemorrhoids. ${ }^{13}$ Euphorbia hirta leaves are recommended in the treatment of various ailments, but in therapeutic doses because of their known toxicity if used in high doses, although there is no scientific evidence.
The healing effects of natural dietary agents are partially due to the constituent phytochemicals. Many studies ${ }^{14}$ demonstrate and describe the various therapeutic effects of plant phytochemicals, which include the treatment and/or prevention of cancer. The most important phytochemicals (phenolic compounds, terpenoids, alkaloids, and organosulfur compounds) are all found in Euphorbia hirta leavess.

Euphorbia hirta also contains plant phytosterols and their derivatives, which have been shown ${ }^{15}$ to possess antioxidant potential, anti-inflammatory activity, and to protect against some illnesses and cancers. Phenolic compounds, most importantly the flavonoids, may protect the human body from oxidative stress that may lead to cancer, aging, and cardiovascular diseases. ${ }^{16}$

The chemopreventive and anti-cancer effects of Cruciferous vegetables have also been attributed to the presence of high levels of organosulfur compounds, ${ }^{21}$ which have been shown to exert diverse biological effects, including induction of carcinogen detoxification, inhibition of tumor cell proliferation, free radical scavenging, induction of cell cycle arrest, and induction of apoptosis.

The oil of the Euphorbia hirta leaves is rich in alpha linolenic acid, and contains an ideal ratio of $\omega-3$ fatty acids (n-3) and $\omega-6$ fatty acids (n-6). ${ }^{22}$ Recent studies ${ }^{22}$ proved the preventive effect of $\omega-3$ polyunsaturated fatty acids, especially alpha linolenic acid, on different types of cancer, including breast, in both animals or cell line models, and in the treatment of cancer. $^{29}$

Glucosinolates, a class of thioglycosides, are major secondary metabolites of Euphorbia hirta leaves and leaves ${ }^{30}$ and have been shown to inhibit carcinogenesis and have chemopreventive effects against the development and proliferation of cancers. ${ }^{6}$

As presented above, some researchers have shown that certain constituents of the Euphorbia hirta plant and the alcoholic extracts of its different parts have chemopreventive and anti-cancer effects, but, to our 
knowledge, no studies exist on the effects of the aqueous extract of $\mathrm{Eu}$ phorbia hirta leaves on the viability and growth of cancer cells. Therefore, the potential of Euphorbia hirta to induce death of human breast cancer cells in tissue culture is investigated here in the hope of finding a natural treatment.

\section{MATERIALS AND METHODS}

\section{Cell lines}

The human breast cancer cell line MCF-7 (Michigan Cancer Foundation-7) (ATCC, Pune), is an epithelial invasive breast ducal carcinoma cell line, which is estrogen and progesterone receptor positive.

Both MCF-7 and MDA MB 231 were cultivated in Dulbecco's minimal essential medium (DMEM) supplemented with 10\% fetal bovine serum (FBS) (both GIBCO, Grand Island, NY, USA), 1\% L-glutamine, $1 \%$ penicillin, and streptomycin and incubated in $5 \% \mathrm{CO}_{2}$ atmosphere, at $37^{\circ} \mathrm{C}$, and $96 \%$ relative humidity.

\section{Preparation of The Aqueous Extract}

Euphorbia hirta leaves were obtained locally and they were powdered using an electric grinder. The extract was prepared by dissolving $1 \mathrm{~g}$ of Euphorbia hirta leaves powder in $99.87 \mathrm{ml}$ of deionized water and adding $0.14 \mathrm{ml}$ of DMSO, thereby leading to a $0.1 \%$ DMSO for the highest used concentration of extract (75\%). Several dilutions of the extract in serumfree medium (SFM) were prepared [extract: SFM (vol/vol); 1:3 (25\% of extract), 1:1 (50\%), and 3:1 (75\%)], and were stored at $-80^{\circ} \mathrm{C}$.

\section{Determination of Cells' Morphology Using Light Microscopy}

To determine the effects of Euphorbia hirta leaves extract on the morphology of the cells, both MCF-7 and MDA MB 231 cells were suspended in DMEM containing 10\% FBS and then leaved on a cover slip placed in a Petridish. After $24 \mathrm{~h}$, the original DMEM was replaced with $5 \mathrm{ml}$ of SFM containing one of the different concentrations of Euphorbia hirta leaves extract $(25 \%, 50 \%$, or $75 \%)$, while the control contained only $0.1 \%$ DMSO in SFM. After $48 \mathrm{~h}$, the medium was discarded, and the cells were then stained with Coomassie blue. Finally, the cells were observed and photographed on an Eclipse E400 light microscope attached to a Nikon F-601 camera.

\section{DNA Extraction, Purification And Electrophoresis}

Both MCF-7 and MDA MB 231 cells $\left(1.5 \times 10^{5}\right.$ cell $\left./ \mathrm{ml}\right)$ were suspended in DMEM containing 10\% FBS, and subsequently cultivated on 6-well plates at $5 \mathrm{ml} /$ well. After $24 \mathrm{~h}$, the original DMEM was replaced with $5 \mathrm{ml}$ of SFM containing a concentration (25\%, 50\%, or 75\%) of Euphorbia hirta leaves extract. The control used was as described above. The cells were treated in a time-or dose-dependent manner. One group of both cells was exposed to $25 \%, 50 \%$, or $75 \%$ extract and incubated for $72 \mathrm{~h}$, while another group of both cells was treated only with $50 \%$ of extract and incubated for 24,48 , or $72 \mathrm{~h}$.

The cells were harvested by adding $1 \mathrm{ml} /$ well of trypsin to separate adherent cells and then $3 \mathrm{ml} /$ well of SFM to stop the effect of trypsin and harvest the cells. The cells were subsequently centrifuged at $1500 \mathrm{rpm}$ for $10 \mathrm{~min}$. Each pellet was washed with PBS and then centrifuged, as above, and the process was repeated. The resultant pellets were stored at $-20^{\circ} \mathrm{C}$ until the time of DNA extraction.

DNA from both types of cells was extracted and purified using a DNA extraction kit according to the manufacturer's protocol. The resultant purified DNA was stored at $-20^{\circ} \mathrm{C}$ until DNA electrophoresis.

Isolated DNA samples were subjected to electrophoresis on a $0.8 \%$ agarose gel for $45 \mathrm{~min}$ at 100 volt. The gel was visualized under UV light following ethidium bromide staining to determine DNA fragmentation.
Quantitative Determination of Apoptosis And Necrosis Using Flow Cytometry

The two major types of cell death, necrosis and apoptosis, produced by the effects of the extract on MCF-7 and MDA MB 231 cells were detected by the CF488A-Annexin V and Propidium Iodide kit by using flow cytometry and fluorescent microscopy (below).

MCF-7 and MDA MB 231 cells $\left(2 \times 10^{5} \mathrm{cell} / \mathrm{ml}\right)$ were cultivated in DMEM containing $10 \%$ FBS, at $10 \mathrm{ml}$ per Petri dish. Upon formation of a monolayer of cells, $10 \mathrm{ml}$ of a concentration $(25 \%, 50 \%$, or $75 \%)$ of Euphorbia hirta leaves extract were added. As above, the control was SFM containing $0.1 \%$ DMSO. After $24 \mathrm{~h}$ of incubation, cells were harvested by the addition of trypsin, centrifuged for $5 \mathrm{~min}$ at $1000 \mathrm{x}$, and finally washed with PBS. Cells were stained according to the kit's protocol, and were analyzed by a BD FACSC an to II Flow Cytometer, at the National Guards Hospital, Jeddah, KSA. The determinations were performed in duplicates.

\section{Quantitative Determination Of Apoptosis and Necrosis Using Fluorescent Microscopy}

MCF-7 $\left(1 \times 10^{5} \mathrm{cell} / \mathrm{ml}\right)$ and MDA MB $231\left(1.5 \times 10^{5} \mathrm{cell} / \mathrm{ml}\right)$ cells in DMEM containing $10 \%$ FBS were added into the wells of 96 -well microtiter plates, at $100 \mu \mathrm{l} /$ well. After $24 \mathrm{~h}$, the original medium was replaced with $100 \mu \mathrm{l}$ of SFM containing different concentrations $(25 \%, 50 \%$ or $75 \%)$ of Euphorbia hirta leaves extract, in addition to the usual control, and allowed to incubate for $24 \mathrm{~h}$. Cells were then washed with PBS and then stained with annexin V and PI according to the instructions of the kit used (above). Finally the stained cells were observed and photographed under an Eclipse 50i Nikon fluorescent microscope equipped with a DSFil digital camera.

\section{Statistical Analysis}

Statistical comparisons of the percentages of living and dead cells were performed using the three-way ANOVA test followed by the Dunnett's multiple comparisons test. For the differences in the results, the Pvalue was used to determine statistical significance. A difference with a $P$-value $<0.05$ was considered statistically significant.

\section{RESULTS}

\section{The Morphology of the Extract on the Morphology of Cells}

Upon the incubation of cells with increasing concentrations of extract, for $48 \mathrm{~h}$, apoptotic cells were more frequently seen. The most common apoptotic morphological changes observed in both cells included chromatin condensation, cytoplasm shrinkage, and loss of normal shape followed by breaking up of the nucleus into discrete fragments by budding of the cell as a whole to produce membrane-bound apoptotic bodies.

Figure 1A: shows that an MCF-7 cell treated with $0.1 \%$ DMSO retains its normal angular or polygonal shape. Most cells have intact and large vesicular nuclei with prominent nucleoli. MDA MB 231 cells treated with $0.1 \%$ DMSO show (Figure 2A) a normal spindle shape and intact large oval, and vesicular nuclei with two prominent nucleoli. MCF-7 (Figure 1B) and MDA MB 231 (Figure 2B) cells treated with 25\% extract show loss of the normal sheet-like growth and most of the remaining few cells had shrunken cytoplasm, condensed chromatin and loss of normal shape.

MCF-7 (Figure 1C) and MDA MB 231 (Figure 2C) cells treated with 50\% extract showed a significant loss of cell processes and marked changes in morphology associated with late stage of apoptosis, such as shrinkage, irregular shape, and condensed and fragmented chromatin and cytoplasm, to produce apoptotic bodies. A marked and visible increase in the number of necrotic cells was observed. Necrotic MCF-7 and MDA MB 231 cells (Figures 1 and 2D, respectively) appeared after incubation with 
A

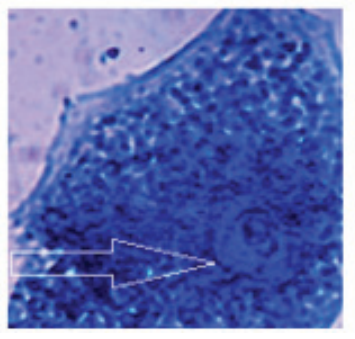

B

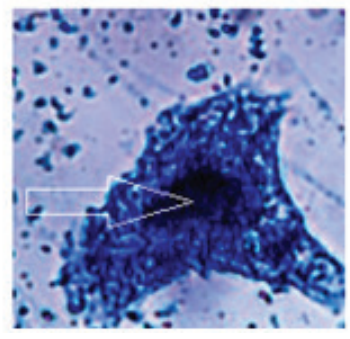

C

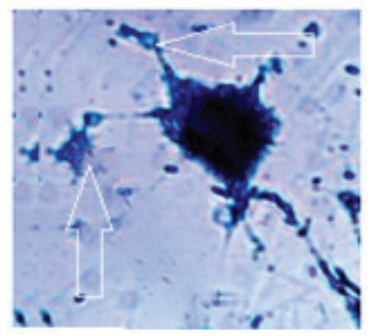

D

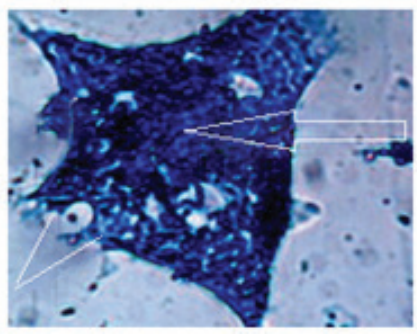

Figure 1 : Effects of L. E hirta leaves extract on the morphology of MCF-7 cells after $48 \mathrm{~h}$ of treatment. The cells were examined under an Eclipse E400 light microscope using a $100 \times$ xobjective lens. (A) Shows an MCF-7 cell treated with $0.1 \%$ DMSO only. The cell has normal angular or polygonal shape with intact and large vesicular nucleus and prominent nucleolus (arrow). (B) Represents an MCF-7 cell treated with $25 \%$ extract that has lost its normal shape and shows a shrunken cytoplasm and condensed chromatin (arrow). (C) Represents an MCF-7 cell treated with 50\% extract that shows evident signs of apoptosis including cytoplasm and chromatin condensation, and fragmentation and formation of apoptotic bodies (lines). (D) Represents an MCF-7 cell treated with $75 \%$ extract that show signs of necrosis. The cell has more or less a normal polygonal shape with a poorly defined nucleus (arrow), clear vesicles in the cytoplasm (line) and disrupted cellmembrane with leaking cell contents (dashed arrows).

A

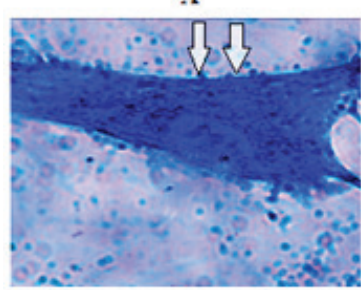

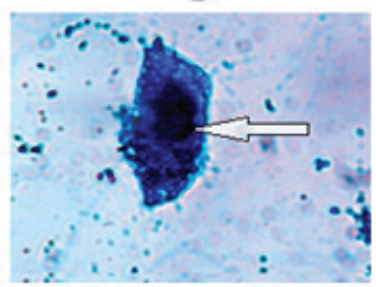

C

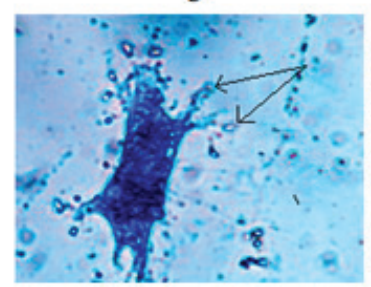

D

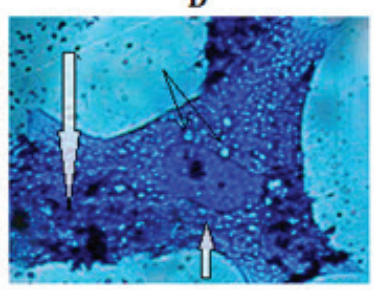

Figure 2 : Effects of E. hirta leaves extract on the morphology of MDA MB 231 cells after $48 \mathrm{~h}$ of treatment. The cells were examined under Eclipse an E400 light microscope using a 100xobjective lens. (A) Represents an MDA MB 231 cell treated with $0.1 \%$ DMSO that shows a normal spindle shape and intact large, oval, and vesicular nucleus with two prominent nucleoli (arrows). (B) Represents an MDA MB 231 cell treated with $25 \%$ extract that lost its normal shape and shows a shrunken cytoplasm and condensed chromatin (arrow). (C) Represents an MDA MB 231 cell treated with 50\% extract with evident signs of apoptosis (cytoplasm and chromatin condensation and fragmentation) and formation of apoptotic bodies (lines). (D) Represents an MDA MB 231 cell treated with $75 \%$ extract that shows signs of necrosis, including clear nucleus (arrow), clear vesicles in the cytoplasm (lines), and disrupted cell membrane with leakage of cell contents (dashed arrow).
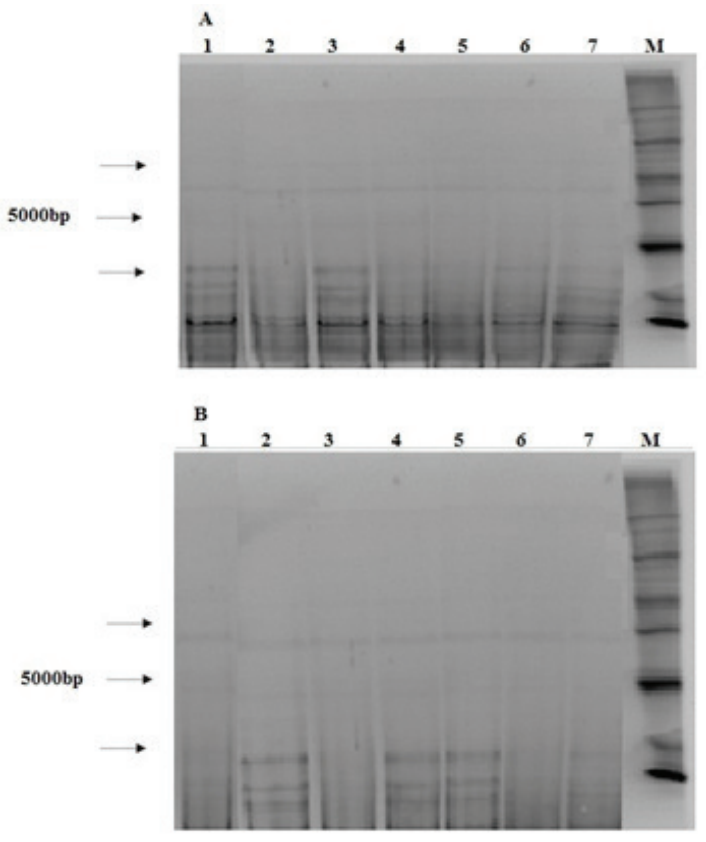

Figure 3: Electrophoresis of DNA extracted from MCF-7 MDA-MB-231 cells after treatment with extract of different concentration and incubation time. Lane 1-: DNA from the cells of control. Lane 2-: DNA treated with $25 \%$ extract for $72 \mathrm{~h}$. Lane 3-: DNA treated with $50 \%$ extract for $72 \mathrm{~h}$. Lane $4-:$ DNA treated with $75 \%$ extract for 72 h. Aim-: 1 KBP DNA marker. Lane 5-: DNA treated with $50 \%$ of extract for 24 h. Lane 6 -: DNA treated with $50 \%$ of extract for 48 h and Lane 7 -: DNA treated with $50 \%$ of extract for $72 \mathrm{~h}$. 


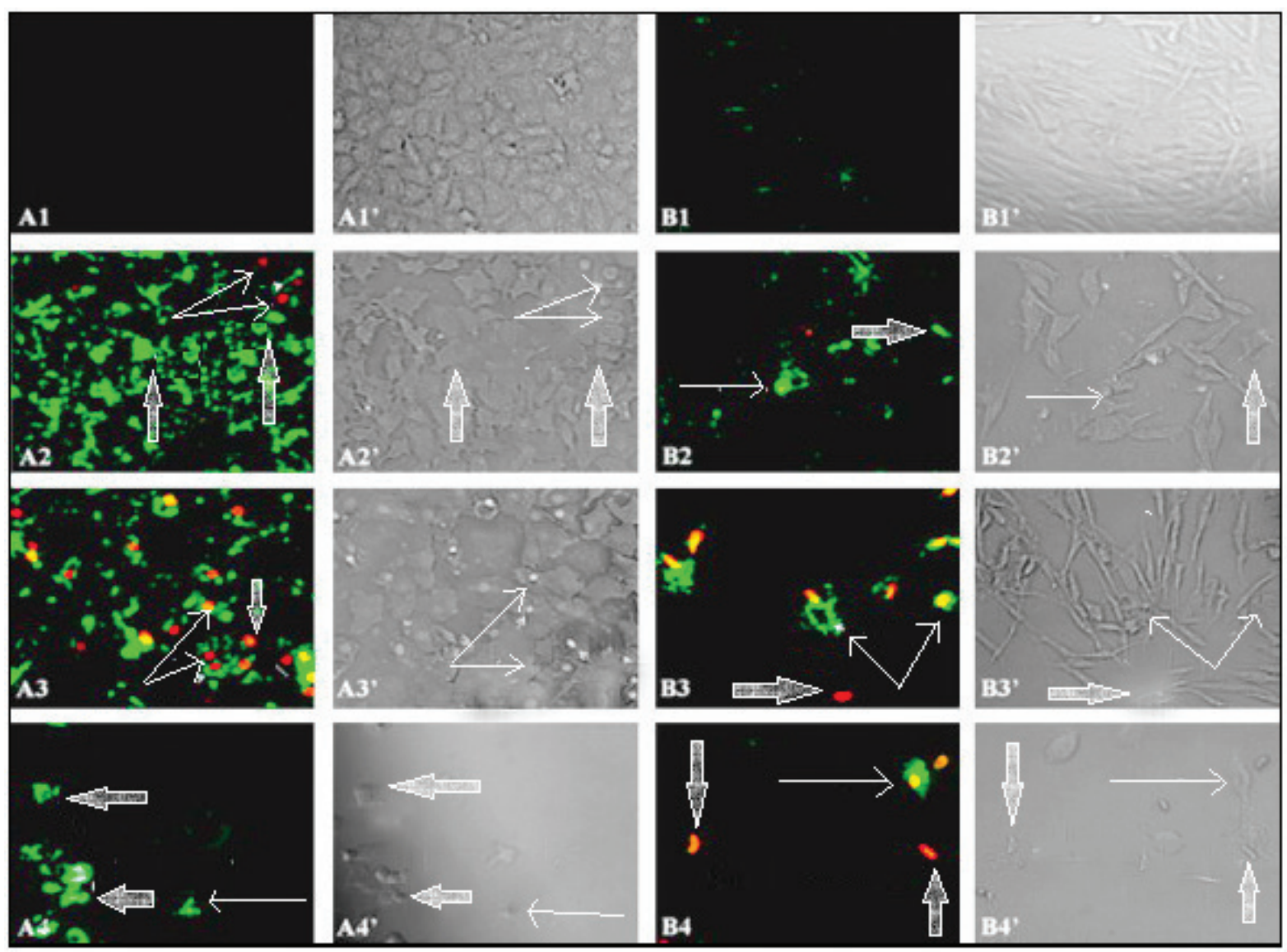

Figure 4 : The extract induced apoptosis and necrosis in both MCF-7 and MDA MB-231 cells after $24 \mathrm{~h}$ of incubation. The cells were examined under a Nikon Eclipse 50i Nikon microscope using a 20xobjective lens. Viable cells do not take any color (Annexin $\mathrm{V}^{-} / \mathrm{PI}^{-}$), early apoptotic cells (Annexin $\mathrm{V}+/ \mathrm{PI}-$ ) are green, late apoptotic cells (Annexin $\mathrm{V}^{+} / \mathrm{PI}^{+}$) are green and orange, and necrotic cells (Annexin $\mathrm{V}-/ \mathrm{PI}+$ ) are orange. (A1-A4) represent MCF-7 cells and (B1-B4) represent MDA MB 231 cells that were treated with extract (control, 25\%,50\%, and 75\% extract, respectively). (A1-A4 and B1-B4) represent fluorescence images and (A $1^{\prime}-A 4{ }^{\prime}$ and $\left.\mathrm{B1}^{\prime}-\mathrm{B} 4^{\prime}\right)$ correspond to interference contrast images. Continuous arrows indicate early apoptotic cells, dashed arrows indicate late apoptotic cells, and dotted arrows indicate necrotic cells.
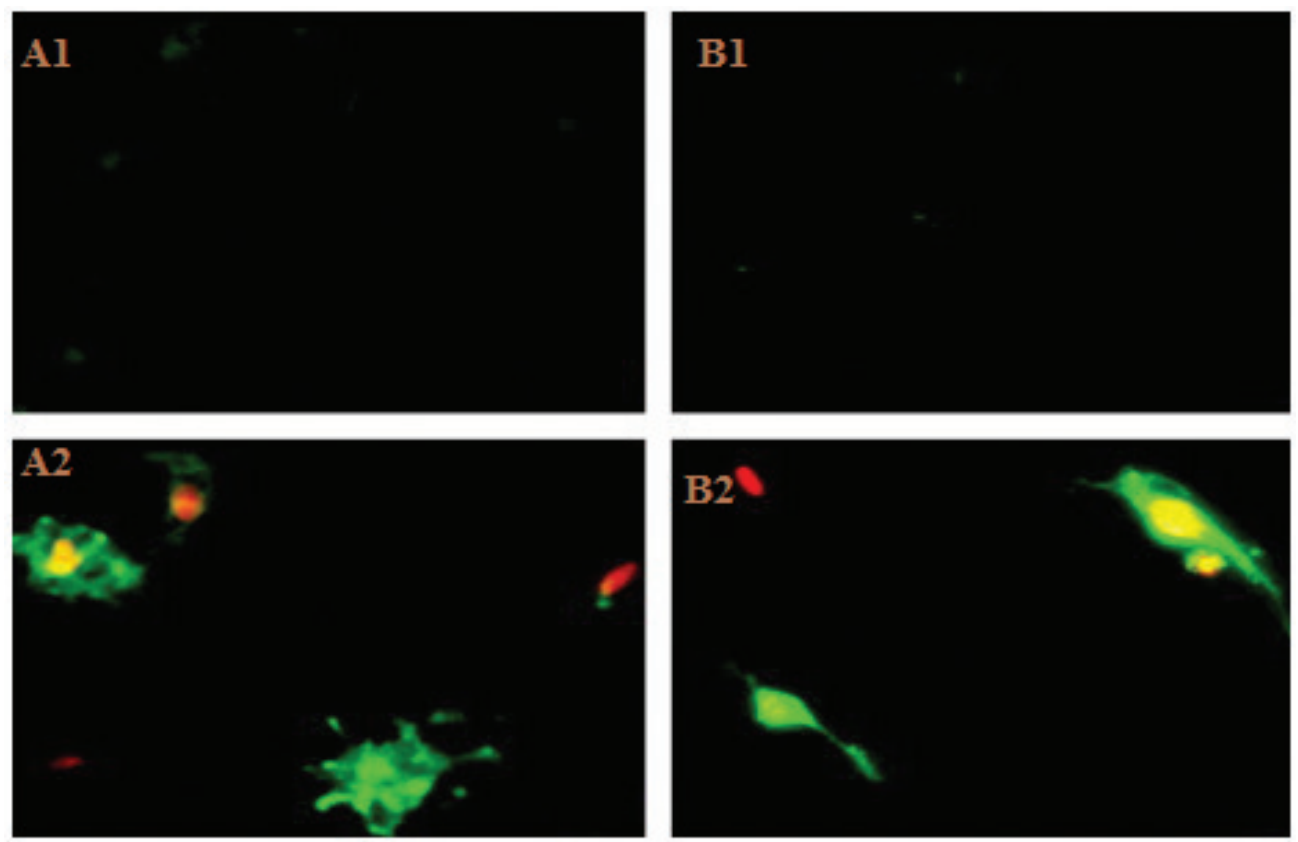

Figure 5 : Fluorescent staining of early and late apoptotic cells and necrotic cells of both MCF-7 and MDA MB 231 cells. (A1 and B1) represent MCF-7 and MDA MB 231 cells, respectively, treated with 0.1\% DMSO only (controls). (A2 and B2) represent MCF-7 and MDA MB 231 cells. 
Table 1 : The percentages of the different types of cell death induced by the extract in both MCF-7 and MDA MB 231 cells stained with Annexin V/Propidium lodide as observed by Flow Cytometry

\begin{tabular}{|c|c|c|c|c|c|c|c|c|}
\hline \multirow{2}{*}{ Cell type Concentration } & \multicolumn{3}{|c|}{ MCF-7 } & \multicolumn{5}{|c|}{ MDA MB 231} \\
\hline & Control & $25 \%$ & $50 \%$ & $75 \%$ & Control & $25 \%$ & $50 \%$ & $75 \%$ \\
\hline$\%$ living cells & \multirow[t]{2}{*}{89.45} & 91.4 & 92 & 89.9 & \multirow{2}{*}{93.2} & 92.5 & 92.9 & 93.8 \\
\hline$P$ & & 0.81 & 0.69 & 1 & & 0.75 & 0.95 & 0.82 \\
\hline$\%$ all dead cells & \multirow{2}{*}{10.55} & 8.7 & 8.1 & 10.2 & \multirow{2}{*}{6.75} & 8.8 & 7.15 & 8.15 \\
\hline$P$ & & 0.83 & 0.7 & 1 & & 0.71 & 0.94 & 0.83 \\
\hline$\%$ early apoptotic cells & \multirow{2}{*}{2.95} & 3.1 & 1.1 & 2.3 & \multirow{2}{*}{1.4} & 2.5 & 0.8 & 1.4 \\
\hline$P$ & & 1 & 0.7 & 0.97 & & 0.97 & 0.47 & 0.38 \\
\hline$\%$ late apoptotic cells & \multirow{2}{*}{0.9} & 1.35 & 1.05 & 1.95 & \multirow{2}{*}{1.85} & 2.2 & 1.5 & 2.6 \\
\hline$P$ & & 0.9 & 1 & 0.51 & & 0.74 & 0.74 & 0.48 \\
\hline$\%$ necrotic cells & \multirow{2}{*}{6.7} & 4.25 & 5.95 & 5.9 & \multirow{2}{*}{3.5} & 4.1 & 4.85 & 4.15 \\
\hline$P$ & & 0.21 & 0.85 & 0.83 & & 8.89 & 0.5 & 0.86 \\
\hline
\end{tabular}

Table 2 : The percentages of both apoptotic (late and early) and necrotic cells induced by the extract in both MCF-7 and MDA MB 231 cells stained with annexin V/propidium iodide as observed by flow cytometry

\begin{tabular}{ccccccccc}
\hline \multirow{2}{*}{ Cell type Concentration } & \multicolumn{4}{c}{ MCF-7 } & \multicolumn{5}{c}{ MDA MB 231 } \\
\cline { 2 - 9 } & Control & $\mathbf{2 5 \%}$ & $\mathbf{5 0 \%}$ & $\mathbf{7 5 \%}$ & Control & $\mathbf{2 5 \%}$ & $\mathbf{5 0 \%}$ & $\mathbf{7 5 \%}$ \\
\hline \% apoptotic cells & 0.9 & 1.35 & 1.05 & 1.95 & 1.85 & 2.2 & 1.5 & 2.6 \\
\% necrotic cells & 6.7 & 4.25 & 5.95 & 5.9 & 3.5 & 4.1 & 4.85 & 4.15 \\
$P$ & 0.445 & 0.917 & 0.508 & 0.381 & 0.728 & 0.621 & 0.186 & 0.177 \\
\hline
\end{tabular}

75\% extract and showed clear cytoplasmic vacuoles, disrupted membrane and leakage of cellular contents.

\section{Chromosomal DNA Fragmentation}

DNA fragmentation is a hallmark feature of apoptosis. Both MCF-7 (Figure 3A) and MDA MB 231 (Figure 3B) cells treated with extract in a time-or dose-dependant manner induced a smear pattern of DNA fragmentation with both high molecular weight DNA and smaller DNA fragments compared with the used DNA ladder that extends from $20 \mathrm{kbp}$ to $75 \mathrm{bp}$. The control for each cell type, treated with $0.1 \%$ DMSO for $72 \mathrm{~h}$, showed clear bands of intact DNA and the smear pattern of damaged DNA.

\section{Determination of Apoptosis and Necrosis Using Cytometry}

Using the three-way ANOVA followed by factorial design, flow cytometry revealed (Table 1) no significant differences between the percentages of living, dead, early and late apoptotic, and necrotic cells for MCF-7 and MDA MB 231 cells treated with $25 \%, 50 \%$, or $75 \%$ extract compared with the respective (untreated) controls. The majority ( $90 \%)$ of detached cells remained unstained, with intact membrane, and no phosphatidylserine translocation suggesting that they were living cells. Flow cytometry also revealed (Table 2) no significant differences between the percentages of both apoptotic (late and early) and necrotic cells for each extract concentration used for the two cell lines.

\section{Determination of Apoptosis and Necrosis Using Fluorescence Microscopy}

Annexin $\mathrm{V}$ is a protein that is conjugated to a green florescent dye to detect apoptosis. Propidium iodide (PI) is a red fluorescent dye that stains DNA of both necrotic and late apoptotic cells with damaged membranes.

Fluorescence microscopy was used to provide qualitative identification of both apoptotic and necrotic deaths of both MCF-7 and MDA MB 231 cells treated for $24 \mathrm{~h}$ with different concentrations (25\%, 50\% or $75 \%)$ of extract (Figure 4). Both MCF-7 and MDA MB 231 cells that were treated with $0.1 \%$ DMSO (Figures 4 and 5A1; and Figures 4 and 5B1, respectively) were viable and negative to annexin $\mathrm{V}$ and PI. A few of both cell types treated with $25 \%$ of extract were positive to annexin V and PI, indicating the presence of early and late apoptotic cells (Figure 4A2 and B2). A high number of both cells treated with $50 \%$ of extract (Figure $4 \mathrm{~A} 3$ and B3; and Figure 5A2 and B2) were positive to annexin V and PI, indicating the presence of early and late apoptotic cells with few necrotic cells. The effect of $50 \%$ of extract was weaker on MDA MB 231 compared with MCF-7 cells (Figure 4A3 and B3, respectively), but the living MDA MB 231 cells had abnormal morphology. The effect of $75 \%$ of extract (Figure 4 A4 and B4) was stronger on both cells, with no living cells and only a few dead cells were observed, and most of these cells were early or late apoptotic cells and necrotic cells.

\section{DISCUSSION}

When cells become old or damaged, they die by apoptosis, necrosis or a combination of the two and are replaced with new cells. On the other hand, cancer cells are immortal since they are resistant to apoptosis. Chemotherapy kills cancer cells through apoptosis and/or necrosis.

The induction of apoptosis and necrosis in MCF-7 and MDA MB 231 cells by the aqueous extract of Euphorbia hirta leaves was monitored by analysis of morphological changes in the cells using light microscopy, DNA fragmentation assay, and florescent stains (Annex-V and VI) using flow cytometry and fluorescent microscopy. Results demonstrated the occurrence of both types of cell death in MCF-7 and MDA MB 231 cells following addition of the extract to the culture medium. Apoptosis was induced when cells were treated with $25 \%$ and $50 \%$ extract, but necrosis was observed mainly after the cells were exposed to elevated concentrations $(75 \%)$ of extract. 
Under light microscopy, the normal angular and spindle shapes of MCF7 and MDA MB 231 cells, respectively, treated with $0.1 \%$ DMSO, were observed, but they were lost after treatment with the extract. The number of dead cells by apoptosis and necrosis increased with increasing concentrations of extract.

Apoptotic cells with their unique morphology, including cell shrinkage, chromatin condensation and finally nuclear and cytoplasm condensation and fragmentation and formation of apoptotic bodies, were observed after $48 \mathrm{~h}$ of exposure to the different concentrations of the extract. At $75 \%$ concentration, the majority of cells die and cells with apoptotic and necrotic morphology were observed. This is in contrast to the $25 \%$ and $50 \%$ concentrations, where apoptosis was the main type of cell death observed.

It is interesting to note that MCF-7 cells are one of the breast cancers that are known to be resistant to currently used chemotherapeutics due to deletion in the CASP-3 gene that leads to an inherited deficiency of caspase-3. Caspase- 3 is commonly activated by numerous death signals and cleaves a variety of important cellular proteins. It is responsible for DNA fragmentation and some of the distinct morphological features of apoptotic cells such as shrinkage and budding. ${ }^{32}$

The results of light microscopy to determine cell morphology proved that apoptotic changes were independent of caspase-3, which is lacking in MCF-7 cells. From these results one can suggest that apoptosis induced by Euphorbia hirta leaves extract does not correlate with the activation of caspase- 3 but may activate different apoptotic pathways and other effector caspases such as caspase- 6 or $-7 .{ }^{35}$

Therefore, there must be other chemical agents in the extract that induce apoptosis and exert the hallmark features of apoptosis independent of the activation of caspase 3. Another researcher ${ }^{34}$ described typical apoptotic morphological changes in MCF-7 cells treated with the chemical compound pyrrolo-1, 5-benzoxazepine (PBOX-6) in a dose-and time-dependent manner. MCF-7 cells also exhibited apoptotic morphological changes when treated with chloroform extract of Gmelinaasiatica. ${ }^{35}$ MDA MB 231 exposed to staurosporine for $8 \mathrm{~h}$ was described by Johansson et al. ${ }^{36}$ to show typical signs of apoptosis as demonstrated by using light microscopy and electron microscopy.

A typical DNA ladder pattern was not evident in either MCF-7 or MDA MB 231 cells treated with Euphorbia hirta leaves extract in a time-or dose-dependent manner. This may indicate that the cells die by apoptosis and/or necrosis, where DNA damage is not a unique feature of apoptosis but can also occur in necrosis. ${ }^{37}$ DNA extracted from apoptotic cells often show a ladder pattern and the presence of a smear pattern may indicate that the apoptotic cells enter into late apoptosis (secondary necrosis) because of the absence of phagocytosis to remove cell remnants. ${ }^{38}$ Or that some cell lines, such as MCF-7, can undergo apoptosis without showing DNA fragmentation due to lack of caspase-3 which is responsible for this feature. ${ }^{32}$ Another explanation may be that the long incubation time of DNA led to lyses of a substantial part of the cell population. The smear pattern was also observed in the controls for both cell types that were treated with $0.1 \%$ DMSO for $72 \mathrm{~h}$, which confirms the previous explanation. The DNAs isolated from the controls of both cell types exhibited one clear band (for each cell types) that pointed to the presence of living cells with intact DNA strand.

DNA fragmentation was induced ${ }^{21}$ in four human breast cancer cell lines (MDA-MB-231, MDA-MB-468, MCF-7, and T47D cells) after treatment with sulforaphane, an isothiocyanate found in Cruciferous vegetables, for $96 \mathrm{~h}$. DNA fragmentation was also detected in Jurkat cells exposed to BITC at different concentrations for $20 \mathrm{~h}$, but not detected at a high concentration. ${ }^{39}$
Detecting apoptosis and/or necrosis by flow cytometry and fluorescent microscopy after staining with fluorescent dyes, both MCF-7 and MDA MB 231 cells treated with different concentrations of Euphorbia hirta leaves extract $(25 \%, 50 \%$, or $75 \%)$ for $24 \mathrm{~h}$ exhibited both apoptotic and necrotic changes.

Flow cytometry showed that the number of dead MCF-7 cells was not significantly different from that found for MDA MB 231 cells. The apoptotic and necrotic cells were observed in both types of cells treated with different concentrations of Euphorbia hirta leaves extract. There were no significant changes in the percentages of different types of dead cells (early and late apoptosis and necrosis) for both MCF-7 and MDA MB 231 treated with different concentrations of extract, compared with the control cells.

Under fluorescent microscopy, after $24 \mathrm{~h}$ of extract exposure, both types of control cells ( $0.1 \%$ DMSO) were viable and did not undergo apoptosis or necrosis. Apoptotic cells decreased and necrotic cells increased with exposure to increasing concentrations of Euphorbia hirta leaves extract. Early and late apoptotic cells were detected at 25\% extract concentration, and early and late apoptotic cells and necrotic cells were observed at 50\% concentration. MCF-7 cells were more affected by the extract than MDA MB 231 at 25\% and 50\%. For both cell types, a fewer number of cells were observed after treatment with $75 \%$ concentration due to the strong effect of this concentration, and most remaining cells were apoptotic or necrotic cells.

Similar results were reported in a study, ${ }^{40}$ using flow cytometry, of HT-29 colorectal cells treated with allylisothiocyanate, an isothiocyanate found in Cruciferous vegetables, for $24 \mathrm{~h}$, which showed no signs of apoptosis, where the percentage of both apoptotic and necrotic cells in untreated control cells was significantly higher than the cells treated with allylisothiocyanate. Allylisothiocyanate increased the percentage of apoptotic cells in a concentration-dependent manner (after $24 \mathrm{~h}$ ) in both prostate PC-3 and LNCaP cells in comparison with control treated with DMSO.$^{41}$ A significant increase in the percentage of apoptosis was observed in the prostate cancer cells (Capan-2) that were treated for $24 \mathrm{~h}$ with BITC in comparison with control. Flow cytometry and fluorescent microscopy of human brain cancer SHG-44 cell line treated with the water extract of Chinese medicine "PingliuKeli" (which is composed of nine plants) for $24 \mathrm{~h}$, after being stained with annexin V and PI, showed both apoptotic and necrotic cells that increased with increasing concentrations of extract. ${ }^{42}$ Fluorescent microscopy indicated ${ }^{43}$ that the methanol extract of adenocalymma alliaceum flowers induce time-dependent apoptosis in both MCF-7 and MDA MB231 breast cancer cells treated for 6 and $12 \mathrm{~h}$, with less prominent necrosis.

\section{CONCLUSION}

Aqueous extract of E. hirta was equally, and even more in some experi $\neg$ ments found effective against MCF-7 cells compared to MDA MB 231 cells. In general, the highest (75\%) dose of extract was cytotoxic for both MCF-7 and MDA MB 231 cells in most assays.

It is recommended that further work be done using the lowest concentration of the extract on MCF-7 and other types of breast cancers and for longer incubation periods. This might help reduce or eliminate the toxic and damaging effects of the high concentrations of the extract on the healthy cells while, at the same time, possibly getting better effects on the cancer cells due to the extended period of incubation. Another area of further research is to work on the active ingredients of the extract with different types of cancer.

\section{ACKNOWLEDGEMENT}

The authors are sincerely acknowledging thanks to HOD, UDPS, for his kindly and timely advice, we are also grateful to UGC New-Delhi for financial support. 


\section{CONFLICT OF INTEREST}

The author declare no conflict of interest.

\section{ABBBREVIATIONS USED}

DMSO: Dimethyl Sulfoxide; FBS: Fetal Bovine Serum; DMEM: Dulbecco's Modified Eagle's Medium; PBS: Phosphate Buffered Saline; PI: Propidium lodide.

\section{ABOUT AUTHORS}

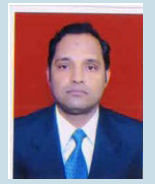

Dr. Debasish Pradhan: Is Specialist in Immunity and Breast Cancer Medicine. He is currently Sr Faculty at Dept. of Pharmaceutical Sciences, UtkalUniversity. He is a recognized expert in nutritional medicine, immunity and cancer. Nine no of PhD degree have been awarded under his Supervision. He has written over 75 articles on natural medicines and one book "Fundamentals and principles in Pharmacology". He has all the degrees and publication in the research of EthnoMedicine/ Herbal Medicine/ Natural Medicine and a total experience of thirteen years.

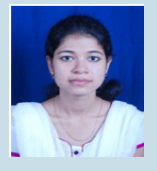

Ms. Bandana Behera: Is a bonafied student of Dept. of Pharmaceutical Sciences, UtkalUniversity. She is continuing as a PG student and continuing research as a co-researcher.

\section{REFERENCES}

1. American Cancer Society. American Cancer Society, Inc.; GA: 2010. Cancer Facts \& Figures 2010

2. Berquin I.M., Edwards I.J., Chen Y.Q. Multi-targeted therapy of cancer by omega-3 fatty acids.Cancer Letters. 2008;269:363-77.

3. Cao P, Cai X, Lu W, Zhou F, Huo J. Growth inhibition and induction of apoptosis in SHG-44 glioma cells by Chinese medicine formula "PingliuKeli" EvidenceBased Complementary and Alternative Medicine. 2010;2011:1-9.

4. Conforti F, loele G, Statti GA, Marrelli M, Ragno G, Menichini F. Antiproliferative activity against human tumor cell lines and toxicity test on Mediterranean di-etary plants. Food and Chemical Toxicology. 2008;46:3325-32.

5. Divisi D, Tommaso SD, Salvemini S, Garramone M, Crisci R. Diet and cancer Acta Biomedica. 2006;77(2):118-23.

6. Diwakara BT, Duttaa PK, Lokeshb BR, Naidu KA. Bio-availability and metabolism of n-3 fatty acid rich garden cress (Lepidium Ehirta) leaves oil in albino rats. Prostaglandins, Leukotrienes and Essential Fatty Acids. 2008;78(2):123-30.

7. Dugasani S.L., Balijepalli M.K., MallikarjunaRao P. Growth inhibition and induction of apoptosis in estrogen receptor-positive and negative human breast carcinoma cells by Adenocalymma alliaceum flowers. Current Trends in Biotechnology and Pharmacy. 2009;3:1-12.

8. Pradhan D, Tripathy G. Anticancer Activity of Limoniaacidissimain Cancer Cell Lines. Tropical Journal of Pharmaceutical Research. 2012;11(3):413-9.

9. Pradhan D, Tripathy G, Pradhan S. Nature-An Immune Booster for Breast Cancer: 2015; Chap-3;73.

10. Pradhan D. Pharmacological effect of Sapindustrifoliatusin mammary cell proliferation. African Journal of Pharmacy and Pharmacology. 2014;8(1); 455-63.

11. Pradhan D, Panda PK, Tripathy G. Evaluation of Immunomodulatory activity of C. Guianensis Aubl. Flowers in rats.: Natural Product Radiance-NISCAIR. 2009;8(1):37-42.

12. Pradhan D, Pradhan RK, Tripathy G, Pradhan S. Inhibition of proteasome activity by the dietary flavonoid Quercetin. Breast Cancer cells and Xenografts. Journal of Young Pharmacists. 2015;7(3);225-33.

13. Gokavi SS, Malleshi NG, Guo M. Chemical composition of garden cress (LepidiumEhirta) leavess and its fractions and use of bran as a functional ingredient. Plant Foods for Human Nutrition (Formerly Qualitas Plantarum). 2005;59(3):105-

14. Hail N., Cortes M., Drake E.N., Spallholz J.E. Cancer chemoprevention: a radical perspective. Free Radical Biology and Medicine. 2008;45:97-110.

15. Hardman WE, Avula CPR, Fernandes G, Cameron IL. Three percent dietary fish oil concentrate increased efficacy of doxorubicin against MDA-MB 231 breast cancer xenografts. Clinical Cancer Research. 2001;7(7):2041-9.

16. Hudaib M, Mohammad M, Bustanji Y, Tayyem R, Yousef M, Abuirjeie M, et al. Ethnopharmacological survey of medicinal plants in Jordan, Mujib nature reserve and surrounding area. Journal of Ethnopharmacology. 2008;120(1):63-71.

17. Jänicke RU, Sprengart ML, Wati MR, Porter AG. Caspase-3 is required for DNA fragmentation and morphological changes associated with apoptosis. The Journal of Biological Chemistry. 1998;273(6):9357-60.
18. Johansson AC, Steen H, Öllinger K, Roberg K. Cathepsin D mediates cytochrome $\mathrm{c}$ release and caspase activation in human fibroblast apoptosis induced by staurosporine. Cell Death and Differentiation. 2003;10(11):1253-9.

19. Jourdan ML, Maheo K, Barascu A, Goupille C, Latour MPD, Bougnoux P, et al. Increased BRCA1 protein in mammary tumours of rats fed marine omega-3 fatty acids. Oncology Reports. 2007;17(4):713-9

20. Kaefer CM, Milner JA. The role of herbs and spices in cancer prevention. Journal of Nutritional Biochemistry. 2008;19:347-61.

21. Karazhiyan $H$, Razavi SMA, Phillips GO, Fang Y, Al-Assaf $S$, Nishinari $K$, et al. Rheological properties of Lepidium Ehirta leaves extract as a function of concentration, temperature and time. Food Hydrocolloids. 2009;23:2062-8.

22. Kassie F, Pool-Zobel B, Parzefall W, Knasmüller S. Genotoxic effects of benzyl isothiocyanate, a natural chemopreventive agent. Mutagenesis. 1999;14(6):595604.

23. Kassie F, Laky B, Gminski R, Mersch-Sundermann V, Scharf G, Lhoste $E$, et al. Effects of garden and water cress juices and their constituents, benzyl and phenethylisothiocyanates, towards benzo(a)pyrene-induced DNA damage: model study with the single cell gel electrophoresis/Hep G2 assay. ChemicoBiological Interactions. 2002;142(3):285-96.

24. Kassie F, Rabot S, Uhl M, Huber W, Oin HM, Helma C, et al. Chemoprotective effects of garden cress (LepidiumEhirta) and its constituents towards 2-amino3-methyl-imidazo[4,5-f]quinoline (IQ)-induced genotoxic effects and colonic preneoplasticlesions. Carcinogenesis. 2002;23(7):1155-61.

25. Kassie F, Uhl M, Rabot S, Grasl-Kraupp B, Verkerk R, Kundi M, Chabicovsky $M$, Schulte-Hermann R, Knasmüller1 S. Chemoprevention of 2-amino3-methylimidazo[4,5-f]quinoline (IQ)-induced colonic and hepatic preneoplastic lesions in the F344 rat by cruciferous vegetables administered simultaneously with the carcinogen. Carcinogenesis. 2003;24(2):255-61.

26. Khan N, Adhami VM, Mukhtar H. Apoptosis by dietary agents for prevention and treatment of cancer. Biochemical Pharmacology. 2008;76(11):1229-333.

27. Matthäus B, Angelini LG. Anti-nutritive constituents in oilleaves crops from Italy. Industrial Crops and Products. 2005;21(1):89-99.

28. Mc Gee MM, Hyland E, Campiani G, Ramunno A, Nacci V, Zisterer DM. Caspase-3 is not essential for DNA fragmentation in MCF-7 cells during apoptosis induced by the pyrrolo-1,5-benzoxazepine, PBOX-6. Federation of European Biochemical Societies. 2002;515(1):66-70.

29. Merlin NJ, Parthasarathy $V$, SanthoshkumarTR. Induction of apoptosis in human breast cancer cell line MCF-7 by phytochemicals from Gmelinaasiatica. African Journal of Biotechnology. 2010;9(28):4451-6.

30. Miyoshi N., Uchida K., Osawa T., Nakamura Y. A link between benzyl isothiocyanate-induced cell cycle arrest and apoptosis: involvement of mitogen-activated protein kinases in the Bcl-2 phosphorylation. Cancer Research. 2004;64:2134$-42$

31. Moghadasian MH. Pharmacological properties of plant sterols: in vivo and in vitro observations. Life Sciences. 2000;67(6):605-15.

32. Shapiro TA, Fahey JW, Wade KL, Stephenson KK, Talalay P. Chemoprotective 
glucosinolates and isothiocyanates of broccoli sprouts. Cancer Epidemiology Biomarkers and Prevention. 2001;10(5):501-8.

33. Sharief M, Gani ZH. Garden cress (LepidiumEhirta) leaves as oral contraceptive plant in mice.;Saudi Medical Journal. 2004;25:965-6.

34. Shoieb A.M., Elgayyar M., Dudrick P.S., Bell J.L., Tithof P.K. In vitro inhibition of growth and induction of apoptosis in cancer cell lines by thymoquinone. International Journal of Oncology.2003;22:107-13

35. Shukla Y., Singh M. Cancer preventive properties of ginger: a brief review. Food and Chemical Toxicology. 2007;45:683-90.

36. Smith TK, Lund1 EK, Parker ML, Clarke RG, Johnson IT. Allylisothiocya $\neg$ natecauses mitotic block, loss of cell adhesion and disrupted cytoskeletal struc $\neg$ ture in HT29 cells.2004;25(8):1409-15

37. Tisdale M.J., Dhesi J.K. Inhibition of weight loss by $\mathrm{u}-3$ fatty acids in an experimental cachexia model. Cancer Research. 1990;50:5022-6.

38. Van Breda SGJ, de Kok TMCM, van Delft JHM. Mechanisms of colorectal and lung cancer prevention by vegetables: a genomic approach. The Journal of Nu- tritional Biochemistry. 2008;19(3):139-57.

39. Warrier PK, Nambiar VPK, Ramankutty C, Nair RV. Indian Medicinal Plants: A Compendium of 500 Species. In: Varier N.V.K., editor. Orient Blackswan; Kottakkal: 1996.

40. Wojdyło A, Oszmianski J, Czemerys R. Antioxidant activity and phenolic compounds in 32 selected herbs. Food Chemistry. 2007;105(3):940-9.

41. Xiao D, Srivastava SK, Lew KL, Zeng Y, Hershberger P, Johnson CS, et al. Allylisothiocyanate, a constituent of cruciferous vegetables, inhibits proliferation of human prostate cancer cells by causing G2/M arrest and inducing apoptosis. Carcinogenesis. 2003;24.

42. Xiao D, Vogel V, Singh SV. Benzyl isothiocyanate-induced apoptosis in human breast cancer cells is initiated by reactive oxygen species and regulated by Bax and Bak. Molecular Cancer Therapeutics. 2006;5(11):2931-45.

43. Zhang R, Loganathan S, Humphreys I, Srivastava SK. Benzyl isothiocyanateinduced DNA damage causes G2/M cell cycle arrest and apoptosis in human pancreatic cancer cells. The Journal of Nutrition. 2006;136(11):2728-34. 